\title{
Electrostatic control on endo/exo selectivity in ionic cycloaddition
}

\author{
V. Tamilmani ${ }^{\text {a,b,1 }}$, C.A. Daul ${ }^{\text {a }}$, P. Venuvanalingam ${ }^{\text {b,* }}$ \\ a Department of Chemistry, University of Fribourg, Chemin de Musée 9, Perolles, CH-1700 Fribourg, Switzerland \\ ${ }^{\mathrm{b}}$ Department of Chemistry, Bharathidasan University, Tiruchirappalli 620 024, India
}

Received 8 August 2005; in final form 24 September 2005

\begin{abstract}
DFT method has been used in combination with various basis sets to model the ionic cycloaddition of cationic heteroaromatic diene, 2,3-dimethylisoquinoliniuim ion with cyclopentadiene with a view to understand the factors that influence the stereochemical outcome of the reaction. Calculations show that this reaction is an inverse electron demand type reaction and it passes through highly asynchronous transition states and mainly electrostatic repulsion govern the endolexo selectivity of the reaction. Endo TS is more destabilized than exo TS due to repulsion between positive charges delocalized over the two reacting partners in the transition state and hence, exo adduct is more preferred than endo adduct in total agreement with experiment.
\end{abstract}

\section{Introduction}

Ionic cycloadditions are reactions in which one of the cycloaddition partners is an ion, either a cation or an anion. Cationic addends have a low-lying LUMO and anionic addends have a high-lying HOMO and this enhances the reactivity of these addends towards addition. Several reactions of this type have been reported in the literature and especially Bradsher and coworkers [1-9] have done lot of work with cationic Diels-Alder reactions. In this category the reaction of 2,3-dimethylisoquinolinium cation (1) with cyclopentadiene $(\mathrm{CP})$ has been investigated by them [1] for understanding its high regio and stereospecificity. They have reported that $\mathrm{CP}$ and $\mathbf{1}$ undergo $\left[2+4^{+}\right]$cationic Diels-Alder reaction and the cycloaddition was strongly regio- and stereoselective in view of uneven distribution of the positive charge in the cation. Initially, these reactions were thought to proceed via a two-step mechanism but subsequent research revealed the absence of any evidence for an intermediate carbonium ion. There were some indi-

\footnotetext{
${ }^{*}$ Corresponding author. Fax: +91 4312407045.

E-mail addresses: Venkatachalam.Tamilmani@unifr.ch (V. Tamilmani), venuvanalingam@yahoo.com (P. Venuvanalingam).

${ }^{1}$ Fax: +41 263008738 .
}

rect evidences that suggested a concerted cycloaddition mechanism for this reaction [10]. Herbert Mayr and coworkers [11] have studied the reaction between $N, N$-dimethylmetheleneammonium cation and $\mathrm{CP}$ and reported that there was unequivocal evidence for a pericyclic transition state. Subsequently, Domingo [12] has further investigated the same reaction and shown that this reaction takes place through concerted asynchronous transition state and no allyl cation could be located. Kavitha and Venuvanalingam [13] has recently shown that ionic cycloadditions will have a greater tendency to follow stepwise path due to the stronger influence of electrostatic forces and CP being a cis-fixed diene has a stronger tendency for concerted mechanism. In the present reaction, one partner is an ion (1) and the other is CP that acts as the nucleophile rather than a dienophile. This has motivated us to look at the (i) mechanism of this reaction and its regio and stereoselectivity (ii) the factors that govern the stereoselectivity. These questions are addressed in the present work.

\section{Computational details}

Density functional theory (DFT) calculations have been carried out using B3LYP method with 6-31G(d), 6$31+\mathrm{G}(\mathrm{d})$ and $6-311 \mathrm{G}(\mathrm{d}, \mathrm{p})$ basis sets. The optimizations 
were carried out using the Berny [14] analytical gradient optimization method. The stationary points were characterized by frequency calculations; minimum and transition structures have zero and one imaginary frequency, respectively. Transition states have been further confirmed by animating the imaginary frequency in MOLDEN. The intrinsic reaction coordinate (IRC) paths were traced to check the energy profiles connecting each transition structure to the two associated minima of the proposed mechanism by using the second-order Gonzalez-Schlegel integration method $[15,16]$. Free energy and enthalpy calculations have been done using thermochemical calculations. Solvent effect has been investigated using SCRF PCM model with acetonitrile as solvent. All calculations have been carried out using GaUSSIAN 03, Revision B.01 and C.01 [17]. Bond orders (BO) have been calculated as the Wiberg [18] indices using NBO analysis, and from them bond formation index $\mathrm{BF}_{i}$ and bond cleavage index $\mathrm{BC}_{j}$ have been calculated as described by Manoharan and Venuvanalingam $[19,20]$.

\section{Results and discussion}

The reaction of 1 with $\mathrm{CP}$ was first studied experimentally by Bradsher and coworkers [1] and they have reported that two stereoselective products were possible; a highly preferred low repulsive exo adduct (2) and a less preferred high repulsive endo adduct (3). This reaction yielded only one adduct that was proved to be exo adduct by NMR and X-ray data. Earlier they [1] believed that the reaction followed stepwise path but the clear stereo chemical outcome of the reaction have led them to suggest a concerted asynchronous mechanism for this reaction. The reaction has been modeled and the reaction scheme is presented in
Fig. 1. Computed activation, reaction energies and frontier orbital energy (FOE) gaps are summarized in Table 1. Bond order analysis data are given in Table 2. Optimized transition state structures are presented in Fig. 2 and 'half-way' structures in the post-TS phase are given in Fig. 3. Calculated schematic energy profile is shown in Fig. 4.

FOE gaps given in Table 1 show clearly that this reaction is an inverse electron demand type reaction. The LUMO of $\mathbf{1}$ is a $\mathrm{C}_{5}-\mathrm{C}_{6}-\mathrm{N}_{7}-\mathrm{C}_{8} \pi^{*}$ orbital and therefore, addition takes place across this unit fixing the regioselectivity. Computed asynchronous TSs shown in the Fig. 2 show that the new bond $\mathrm{C}_{8}-\mathrm{C}_{10}$ is formed much faster than the other new bond $\mathrm{C}_{5}-\mathrm{C}_{9}$ and this indicates that the most electron deficient carbon atom $\mathrm{C}_{8}(0.0667)$ of the cation first attacks one $\pi$ carbon of $\mathrm{CP} \mathrm{C}_{10}(-0.2646)$ and then the second new bond forms at a slower pace. It is a one step (concerted) two stage process in which the first stage is the electrophilic addition. The length of the $\mathrm{C}_{8}-\mathrm{C}_{10}$ forming bond at endo TS is $1.901 \AA$ and that for the exo TS is $1.908 \AA$ while the distance between the $\mathrm{C}_{5}$ and $\mathrm{C}_{9}$ atoms are 2.958 and $2.984 \AA$, respectively. Calculations show that

Table 1

Calculated activation, reaction energies $(\mathrm{kcal} / \mathrm{mol})$, frontier orbital energy gaps $(\mathrm{eV})$

\begin{tabular}{|c|c|c|c|c|c|c|}
\hline \multirow[t]{2}{*}{ Method } & \multicolumn{2}{|l|}{$\Delta E^{\ddagger}$} & \multicolumn{2}{|l|}{$\Delta E_{r}$} & \multirow[t]{2}{*}{$\Delta E_{1}^{\mathrm{a}}$} & \multirow[t]{2}{*}{$\Delta E_{2}{ }^{b}$} \\
\hline & Exo & Endo & Exo & Endo & & \\
\hline B3LYP/6-31G(d) & 13.35 & 15.33 & -8.41 & -9.12 & 10.16 & 3.15 \\
\hline B3LYP/6-311G(d,p) & 16.56 & 17.95 & -5.02 & -5.79 & & \\
\hline B3LYP/6-31 + G(d) & 16.26 & 17.72 & -5.67 & -6.41 & & \\
\hline B3LYP/6-31 + G(d) & 20.67 & 21.73 & -6.41 & -2.64 & & \\
\hline
\end{tabular}

(in acetonitrile)

a $E_{\text {HOMO }}($ diene $)-E_{\text {LUMO }}($ dienophile).

${ }^{\mathrm{b}} E_{\mathrm{HOMO}}($ dienophile $)-E_{\mathrm{LUMO}}($ diene $)$

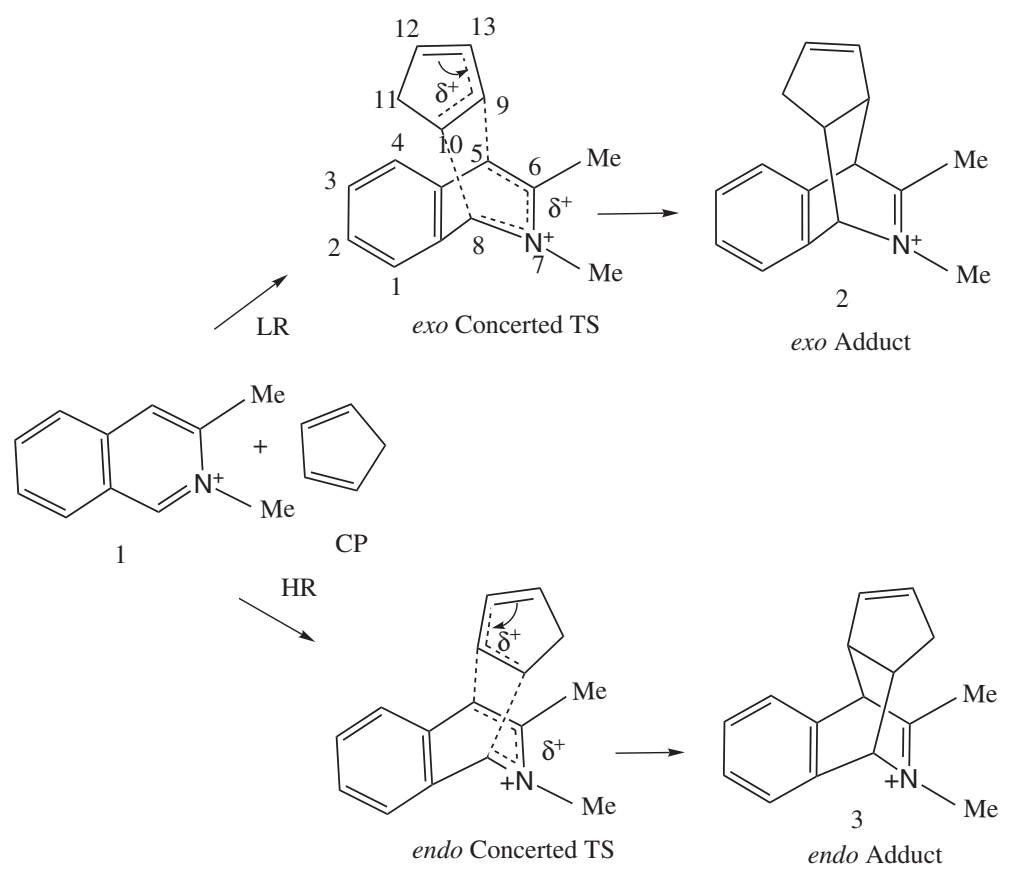

Fig. 1. Possible reaction pathways for the $\left[2+4^{+}\right]$Diels-Alder reaction between cyclopentadiene and 2,3-dimethylisoquinolinium ion. 
Table 2

Percentage of bond formation and cleavage of selected bonds in the TSs of the reaction of cyclopentadinene with 2,3-dimethylisoquinoliniuim ion

\begin{tabular}{|c|c|c|c|c|c|c|c|c|c|}
\hline \multirow[t]{2}{*}{ Species } & \multicolumn{3}{|l|}{$\mathrm{BF}_{i}$} & \multicolumn{3}{|l|}{$\mathrm{BC}_{i}$} & \multirow[t]{2}{*}{$\mathrm{BF}_{\mathrm{Ave}}$} & \multirow[t]{2}{*}{$\mathrm{BC}_{\mathrm{Ave}}$} & \multirow[t]{2}{*}{$\mathrm{BFC}_{\text {Ave }}$} \\
\hline & $\mathrm{N}_{7}-\mathrm{C}_{6}$ & $\mathrm{C}_{10}-\mathrm{C}_{8}$ & $\mathrm{C}_{9}-\mathrm{C}_{5}$ & $\mathrm{C}_{8}-\mathrm{N}_{7}$ & $\mathrm{C}_{6}-\mathrm{C}_{5}$ & $\mathrm{C}_{10}-\mathrm{C}_{9}$ & & & \\
\hline Exo TS & 11.58 & 59.42 & 10.45 & 55.07 & 7.85 & 60.48 & 27.15 & 41.13 & 34.14 \\
\hline
\end{tabular}
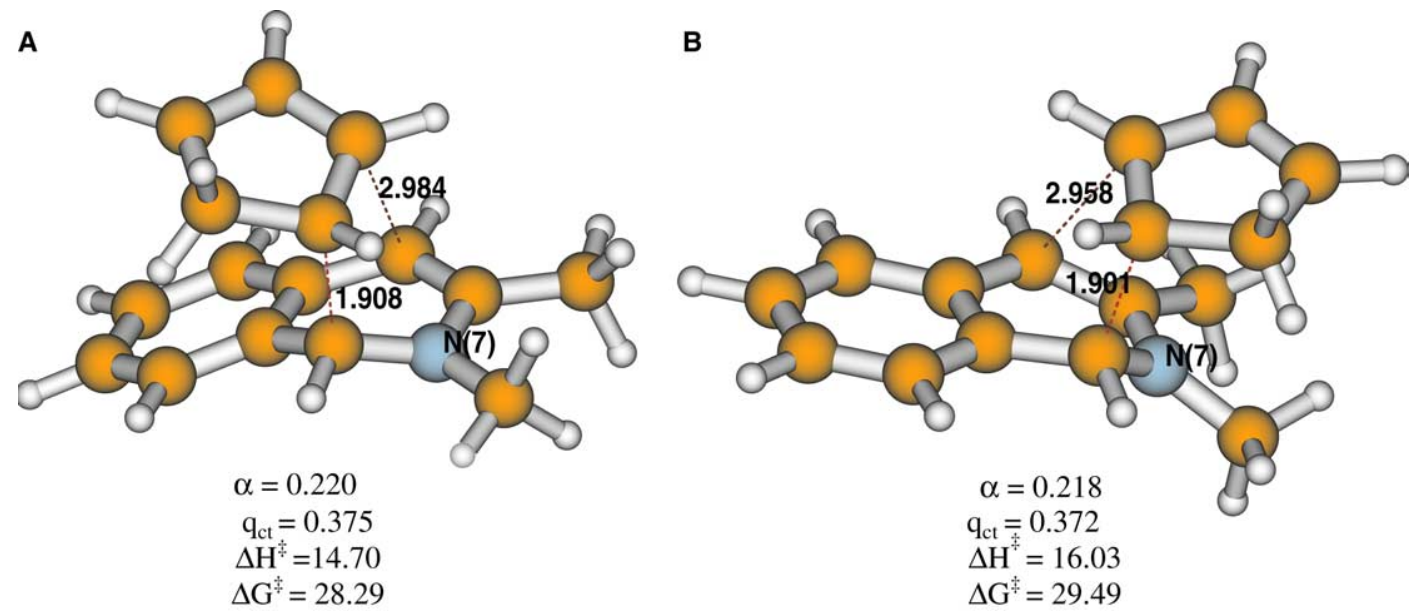

Fig. 2. B3LYP/6-31G(d) Optimized transition states, degree of asynchronicity $(\alpha)$, quantum of charge transfer $\left(q_{\mathrm{ct}}\right)$, activation enthalpy and free energy (kcal/mol). (A) Exo TS. (B) Endo TS (Asynchronicity $\alpha$ is calculated as $|a-b| /(a+b)$, where $a$ and $b$ are the newly forming bond lengths as cited in Ref. $[20])$.
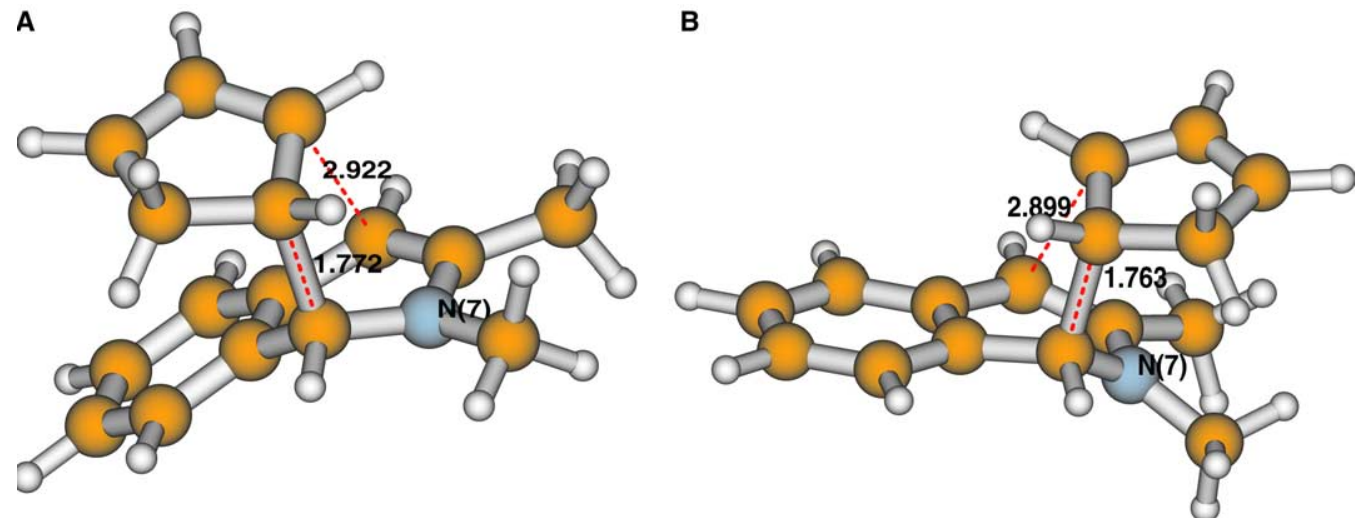

Fig. 3. Structures of the species that are at 'halfway' between the TS and the product: (A) Low repulsion path species. (B) High repulsion path species.

the charge transfer is 0.375 and 0.372 , respectively, in the exo and endo TSs shown in Fig. 2.

Stereoselectivity rule [1] for ionic cycloaddition states that 'If two geometrical isomers are possible the transition states differ in the distances between the centers of receding and developing positive charge, then the geometrical isomer formed in the larger amount will be that with the greater distance between the charge centers in the transition state'. According to this rule in the present case, where exo adduct is preferentially formed and therefore, greater distance between the charge centers should occur in the exo TS. Calculations show that the distance between the $\mathrm{N}_{7}$ and $\mathrm{C}_{12}$ in the exo and endo TSs are 4.51 and $3.41 \AA$, respectively. This is in total accordance with the stereoselectivity rule mentioned above. Computed activation barriers listed in Table 1 show that endo TS is destabilized by 1-2 kcal/mol compared to exo TS by columbic repulsion between the positively charged fragments and therefore, formation of exo adduct is kinetically favoured as observed experimentally. Computed enthalpy of activation also reflects the same. Thermodynamically both adducts have been found to be equally stable. Inclusion of solvent effects through PCM calculations with acetonitrile as solvent did not alter the endolexo selectivity. However, it increases the activation barrier as a consequence of a larger solvation of the cation 1 than TS, because of the large delocalisation 


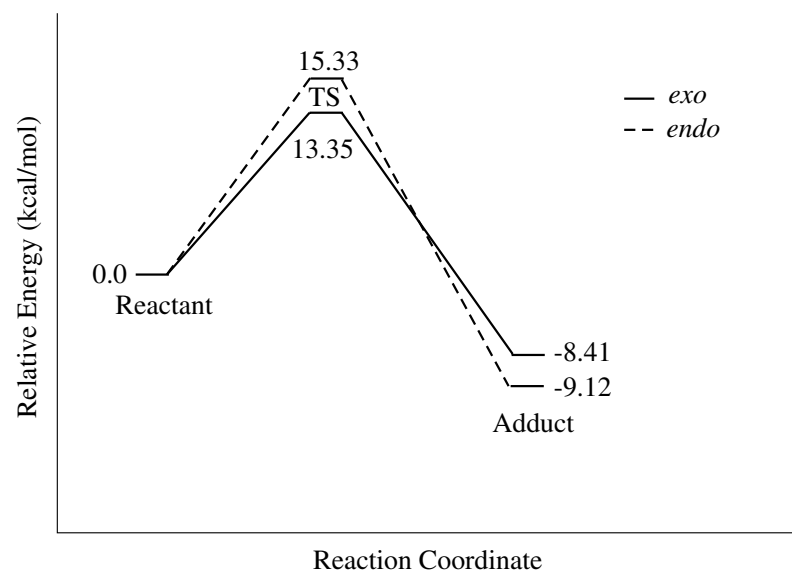

Fig. 4. Schematic energy profile for the $\left[2+4^{+}\right]$Diels-Alder reaction between cyclopentadiene and 2,3-dimethylisoquinolinium ion.

of the positive charge at the later as reported by Domingo [21]. Analysis of vibration frequencies reveal that the atomic motions in the TSs are mainly with the $\mathrm{C}_{10}-\mathrm{C}_{8}$ and the $\mathrm{C}_{9}-\mathrm{C}_{5}$ vibration is very less in magnitude.

Computed $\mathrm{BF}_{i}, \mathrm{BC}_{j}$ and $\mathrm{BFC}_{\mathrm{Ave}}$ values presented in Table 2 have been used to get a clear idea about the bond formation and cleavage of various bonds in the reaction. The $\mathrm{BO}$ value for $\mathrm{C}_{10}-\mathrm{C}_{8}$ forming bond in both the TSs shown in Fig. 2 is 0.5726 while that for $\mathrm{C}_{9}-\mathrm{C}_{5}$ is 0.1038 . The $\mathrm{BFC}_{\mathrm{Ave}}$ values reveal the TSs are early transition states.

The IRC calculations provide the geometry of the points 'halfway' between the TS and the cycloadducts (2) and (3) as shown in Fig. 3. These geometries that are located in a smooth drop in energy after the barrier height show that $\mathrm{C}_{10}-\mathrm{C}_{8}$ bond is formed very fast about $1.77 \AA$ on the other hand $\mathrm{C}_{9}-\mathrm{C}_{5}$ is very delayed and the distance is $2.9 \AA$. Moving the reacting system from the transition state towards the product side show the gradual increase in the formation of the $\mathrm{C}_{9}-\mathrm{C}_{5}$ bond and this confirms that the TSs obtained are indeed concerted asynchronous TSs and not stepwise TSs. This point fixes the mechanism as concerted.

\section{Conclusions}

In this Letter, the cationic cycloaddition between 2,3dimethylisoquinolinium cation and CP has been modeled at B3LYP level with different basis sets and including acetonitrile as solvent using PCM model. Computed results reveal that this reaction is an inverse electron demand reaction and follows highly asynchronous concerted mechanism. Our calculations reveal that the high repulsive forces at the endo TS makes the exo TS to be preferred, in good agreement with the experiments as well as in accordance with the stereoselectivity rule.

\section{Acknowledgments}

This work has been supported by the Swiss National Science Foundation, the Federal Department for Development and Cooperation and CSIR, India through major research Grant No. 01(1649)/00/EMR-I. We also thank the referee for the valuable comments.

\section{References}

[1] C.K. Bradsher, F.H. Day, A.T. McPhail, P.S. Wong, J. Chem. Soc., Chem. Commun. 5 (1973) 156.

[2] R.R. Schmidt, Tetrahedron Lett. 9 (1968) 3443.

[3] C.K. Bradsher, T.W. Solomons, J. Am. Chem. Soc. 80 (1958) 933.

[4] C.K. Bradsher, J.A. Stone, J. Org. Chem. 34 (1969) 1700.

[5] I.J. Westerman, C.K. Bradsher, J. Org. Chem. 36 (1971) 969.

[6] C.K. Bradsher, F.H. Day, Tetrahedron Lett. 12 (1971) 409.

[7] C.K. Bradsher, F.H. Day, A.T. McPhail, P. Wong, Tetrahedron Lett. 12 (1971) 4205

[8] I.J. Westerman, C.K. Bradsher, J. Org. Chem. 43 (1978) 3002

[9] I.J. Westerman, C.K. Bradsher, J. Org. Chem. 44 (1979) 727.

[10] C.K. Bradsher, G.L.B. Carlson, N.A. Porter, I.J. Westerman, J. Org. Chem. 43 (1978) 822.

[11] H. Mayr, A.R. Ofial, J. Sauer, B. Schmied, Eur. J. Org. Chem. (2000) 2013.

[12] L.R. Domingo, J. Org. Chem. 66 (2001) 3211.

[13] K. Kavitha, P. Venuvanalingam, Int. J. Quantum Chem. 104 (2005) 64.

[14] H.B. Schlegel, J. Comp. Chem. 3 (1982) 214.

[15] C. Gonzalez, H.B. Schlegel, J. Phys. Chem. 94 (1990) 5523.

[16] C. Gonzalez, H.B. Schlegel, J. Chem. Phys. 95 (1991) 5853.

[17] M.J. Frisch et al., Gaussian 03, Revision C.02, Gaussian, Inc., Wallingford, CT, 2004.

[18] K. Wiberg, Tetrahedron 24 (1968) 1083.

[19] M. Manoharan, P. Venuvanalingam, J. Mol. Struct. 394 (1997) 41.

[20] M. Manoharan, P. Venuvanalingam, J. Chem. Soc., Perkin Trans. 2 (1997) 1799.

[21] L.R. Domingo, M. Oliva, J. Andres, J. Org. Chem 66 (2001) 6151. 